\title{
La Humanidad, El Bosque, El Cosmos, Los Dioses
}

Humanity, The Forest, The Cosmos, The Gods

Aldo Vivar-MendozA ${ }^{1}$

"Por su inconfundible voz poética, que, con una belleza austera, convierte en universal la existencia individual."

Academia Sueca (Octubre 8, 2020)

Resumen

El autor nos presenta a Louise Glück, poetisa norteamericana, poco conocida en nuestro medio, y ganadora del premio Nobel de Literatura 2020. Sucintamente, nos relata como ciertos pasajes de la vida y de su afición por la mitología griega y por la naturaleza influyeron notoriamente en su producción literaria.

Palabras claves: Premio Nobel, literatura, Louise Glück, poesía.

\section{Abstract}

The author introduces us to Louise Glück, an American poet, little known in our country, and winner of the 2020 Nobel Prize in Literature. Succinctly, he tells us how certain passages of Glück's life and her love for Greek mythology and nature significantly influenced her literary production.

Keywords: Nobel Prize, Literature, Louise Glück, Poetry.

as frases con las que los académicos suecos condensan el significado de la obra de sus galardonados son casi una marca registrada. Es el mismo estilo

1 Médico internista. Departamento de Medicina, Hospital Nacional Arzobispo Loayza. Universidad Peruana Cayetano Heredia, Lima, Perú. utilizado para los premios científicos, pero en el de literatura adquiere un sentido especial. Como es casi usual, los premios Nobel de literatura nos descubren a autores desconocidos para el gran público y también para los aficionados. En este caso con la poesía, no siendo menor que la narrativa, tiene una audiencia limitada $y$, para muchos, fue la primera vez que se conocía de la galardonada. Louise Glück no escapa la tendencia, poeta estadounidense, casi no leída más allá de sus 
fronteras. En los Estados Unidos es reconocida y premiada. En el mundo hispano, su obra fue publicada por editorial Pre-Textos, cuyos libros poseen una pulcra edición como característica, como particularidad sus obras han sido traducidas por poetas, entre ellos, el peruano Eduardo Chirinos.

Louise Glück es la cuarta mujer en recibir el premio Nobel de Literatura en los últimos diez años, luego de Alexievich, Munro y Tokarczuck, y la decimosexta en toda la historia del premio (113 ocasiones). Esta década es la mayor en número de mujeres premiadas, en las previas 1990-2000 y 20002010, con tres galardonadas por periodo. Como dato anecdótico, los editores de PreTextos declararon a la prensa que vendieron más libros inmediatamente después de ser anunciado el premio que en todo el tiempo que llevaba publicada. Lamentablemente, esta ilusión duró poco. Glück tiene como agente literario a Andrew Wylie, más conocido como el Chacal en los medios editoriales. Días después de conocido el premio se conoció que Glück dejaba Pre-Textos, en una trama algo confusa que alegaba un no pago de derechos de publicación y un correo electrónico nunca respondido por la editorial española. De acuerdo al rompimiento del compromiso, Pre-Textos no podía continuar vendiendo sus libros. Al parecer, Wylie ya venía buscando nuevo editor meses antes de octubre, fecha de declaración del premio, sin comunicación previa a Pre-Textos, siendo elegida la editorial Visor de poesía.

Mientras tanto, en Lima, sólo una librería contaba con ejemplares que se agotaron días después de conocido el premio. Por ello, la única manera de conocer la obra de Glück era a través de páginas de internet $\mathrm{y}$, sobre todo, del portal web de la revista New Yorker, donde Glück es asidua colaboradora desde hace 50 años. Cuarentenas más y menos, la reapertura de librerías ha permitido encontrar sus libros publicados por Pre-textos, todos en una impecable edición bilingüe, donde se puede contrastar el original con la reinterpretación del traductor.

Louise Elizabeth Glück, nació el 22 de abril de 1943 en New York y creció en Long Island. $\mathrm{Su}$ padre fue hijo de un inmigrante judío procedente de Hungría. Louise estudió en la escuela secundaria de Hewlett en New York, graduándose en 1961, y ya en la escuela se daba tiempo para remitir sus poemas a revistas literarias.

Durante la vida con sus padres se resaltan dos aspectos: su gran afición por la lectura, sobre todo, la mitología griega y la Biblia (acaso la razón por la que su hijo se llama Noé); el segundo, que ocurrió durante su adolescencia: la confrontación para escapar la dominación de su madre, la mujer que le enseñó a leer a ella y su hermana alentándolas hacia la lectura de los clásicos. De niña Louise leyó a Shakespeare, a Blake, Keats, Yeats y Elliot, a quienes reconoció como su voz, la tradición de la lengua que ella consideraba como natal. Cuenta Louise, en el ensayo Education of a Poet en su libro Proofs and Theories, que su madre intentaba corregir los giros líricos de sus poemas como intentando imponer la "escritura correcta".

Esta adolescencia turbada trajo como consecuencia el desarrollo de anorexia nerviosa, según Glück porque "necesitaba sacarse a su madre de encima". Si la histeria fue la enfermedad psiquiátrica del siglo XIX, la anorexia lo fue la del siglo XX, que en el caso de Glück fue una forma de liberación y una forma de negar su desarrollo como mujer-cuerpo, suprimir la feminidad para no exponerse a la dominación machista. Para ella, el ayuno era una forma de construcción del yo, libre de 
toda dependencia. Al notar la disminución progresiva e incontrolable de su peso, más allá de su voluntad, y alcanzar un mínimo crítico vislumbró la posibilidad de morir, algo que no deseaba pero que irónicamente fue pensada como la patética metáfora de separarse de su madre.

Dedication to Hunger de su tercer libro Descending figure ${ }^{1}$, nos habla de ello:

\section{It begins quietly \\ in certain female children: \\ the fear of death, taking as its form \\ dedication to hunger, \\ because a woman's body \\ is a grave; it will accept \\ anything. I remember \\ lying in bed at night \\ touching the soft, digressive breasts, \\ touching, at fifteen, \\ the interfering flesh \\ that I would sacrifice \\ until the limbs were free \\ of blossom and subterfuge: I felt \\ what I feel now, aligning these words- \\ it is the same need to be perfect, \\ of which death is the mere byproduct.}

La rebeldía inicial hacia sus padres se transformó en pedido de ayuda, era una época donde no se hablaba mucho de anorexia y la discusión sobre el tema no era abierta como ahora. Era su último año de la secundaria, que abandonó para dedicarse a seguir las terapias de psicoanálisis. A sus diecisiete años, Louise no rompía las reglas que un adolescente trasgrede, era demasiado rígida

1 Comienza silenciosamente/ en ciertas niñas: / el miedo a morir, tomando la forma/ de una consagración al hambre, / porque el cuerpo femenino/ es una tumba; aceptaré/ cualquier cosa. Recuerdo/ recostada en la cama en la noche/ tocando los blandos y digresivos pechos/ tocando a los quince, / esa carne intrusa/ que sacrificaría/ hasta que las extremidades queden libres / del florecimiento y el subterfugio: Sentí/ lo que siento ahora, alineando estas palabras-/ es la misma necesidad de ser perfecta, / de la cual la muerte es una mera consecuencia. y autoprotectora y esto se reflejaba en sus poemas, no tocaban sus problemas internos fundamentales, "eran rígidos, metódicos, casi místicos" a decir de la propia Louise.

El psicoanálisis, siete años de terapia, mejoró la salud de Louise pero le generó un bloqueo creativo. Al final de la terapia se sentía tan bien que temía ser tan feliz que le impediría escribir, sabiamente su psicoanalista le dijo que el mundo le daría el dolor suficiente para escribir. Y así fue.

Glück tomó inicialmente la escritura como una venganza contra las circunstancias. Ingresó a Sarah Lawrence College y luego a la Universidad de Columbia, la que dejó sin obtener la licenciatura. Además, se matriculó en talleres de poesía en la Escuela de Estudios Generales de Columbia con los poetas Leonie Adams y, luego, con Stanley Kunitz, quienes la ayudaron a perfilar su estilo.

Su primer libro, Firstborn (1968) está escrito con acritud confesional y utilizando varias primeras personas, el tono áspero de sus poemas incomodó a algunos críticos, pero ya se advertía un tono coloquial y directo que iría perfeccionando con el tiempo, así como el contenido temático de su poesía, su lenguaje y estilo. Este libro, que toca el aspecto negativo de la feminidad y el rol de la mujer en la sociedad, le valió el premio de la Academy of American Poets. Glück trabajó como secretaria para tener tiempo libre y escribir, para entonces vivía en Massachusetts y fue invitada al Goddard College en Vermont a un encuentro de poetas, en aquella ciudad encontró la paz que requería para escribir y se mudó a Vermont, donde se embarcó en la enseñanza con el temor de que esto le produjera otro bloqueo creativo pero, contrariamente a ello, la experiencia docente fue liberadora y le dio un impulso adicional a la escritura. Enseñó poesía en numerosos 
colegios e incluso en la Universidad de Iowa. Por esos años publicó The House of Marshland, The Garden y Descending figure. Luego de estas publicaciones pasaron cinco años para publicar The triumph of Achilles (1985), libro que le valió el National Book Award.

\section{The triumph of Achiles ${ }^{2}$}

In the story of Patroclus

no one survives, not even Achilles

who was nearly a god.

Patroclus resembled him; they wore

the same armor.

Always in these friendships

one serves the other, one is less than the other:

the hierarchy

is always apparent, though the legends

cannot be trusted--

their source is the survivor,

the one who has been abandoned.

What were the Greek ships on fire

compared to this loss?

In his tent, Achilles

grieved with his whole being

and the gods saw

he was a man already dead, a victim

of the part that loved,

the part that was mortal.

Ararat (1990) le valió el Bobbit Prize de la Biblioteca del Congreso, una colección de poemas que habla de su familia, de la muerte del padre, de la relación con su madre y su hermana, de la muerte de su hermana al nacer. En aquellos poemas aparecen subrepticiamente imágenes de mitos clásicos griegos que una

2 En la historia de Patroclo/ nadie sobrevive, ni siquiera Aquiles/ quien era un semidiós./ Patrocolo se parecía a él; usaron/la misma armadura/ Siempre en estas amistades / uno sirve al otro, uno es menos que el otro:/ la jerarquía/ es siempre aparente; aunque en las leyendas / no puede confiarse / ya que su fuente es el sobreviviente,/ quien ha sido dejado solo. / ¿Qué eran los barcos griegos incendiados/ comparados con esa pérdida?/ En su tienda, Aquiles/ se afligía con todo su ser/ y los dioses lo vieron/ él era ya un hombre muerto, una víctima/ de su parte que amó/ de la parte que era mortal. potencia particular a sus reflexiones sobre la vida y la muerte.

\section{Confesion $^{3}$}

To say I'm without fear--

It wouldn't be true.

I'm afraid of sickness, humiliation.

Like anyone, I have my dreams.

But I've learned to hide them,

To protect myself

From fulfillment: all happiness

Attracts the Fates' anger.

They are sisters, savages--

In the end they have

No emotion but envy.

En 1992 publicó The Wild Iris por el que recibió el Pulitzer Prize, así como el William Carlos Williams Prize otorgado por The Poetry Society of America, Williams (1883-1963), uno de los poetas favoritos de Glück, fue hijo de madre portorriqueña dedicada al arte. Williams ejerció la medicina también con éxito $\mathrm{y}$ tiene unos cuentos que deben leerse en toda facultad de medicina.

\section{The wild Iris ${ }^{4}$}

At the end of my suffering

there was a door.

Hear me out: that which you call death

3 Decir que no tengo miedo/ no sería cierto. / Temo a la enfermedad, a la humillación./ Como cualquiera, tengo mis sueños./ Pero he aprendido a ocultarlos, / para protegerme/ del esplendor: toda felicidad/atrae la ira de las Parcas./ Hermanas salvajes-/Que finalmente no tienen emociones solo envidia.

4 Al final de mi sufrimiento/ había una puerta/ Escúchame: eso que llamas muerte/ lo recuerdo/ arriba, ruidos, ramas de pino moviéndose/ Luego nada, el débil sol/ parpadeó sobre la superficie seca./ Es terrible sobrevivir/ como conciencia/ sepultada en la tierra oscura./ Entonces se todo terminó: lo que temías / ser un alma e incapaz/ de hablar, terminó abruptamente/ la tierra yerta/ inclinada un poco. Y lo que imaginé eran/ pájaros se arrojaban sobre los arbustos. / Tú que no recuerdas/ la transición al otro mundo/ Te digo y podría hablar otra vez: / lo que retorna del olvido retorna/ para encontrar una voz: / desde el centro de mi vida brotó / un gran manantial, de sombras/ azul intensas sobre celeste agua de mar. 
I remember.

Overhead, noises, branches of the pine shifting.

Then nothing. The weak sun

flickered over the dry surface.

It is terrible to survive

as consciousness

buried in the dark earth.

Then it was over: that which you fear, being

a soul and unable

to speak, ending abruptly, the stiff earth

bending a little. And what I took to be

birds darting in low shrubs.

You who do not remember

passage from the other world

I tell you I could speak again: whatever

returns from oblivion returns

to find a voice:

from the center of my life came

a great fountain, deep blue

shadows on azure seawater.

Iris, además de definir a una parte del ojo, le da nombre a una serie de plantas con rizoma cuyas flores son de distintos colores. En The Wild Iris, la narradora coloca su mirada estética y moral en la naturaleza, el recorrido a través de diversas flores como el lirio, la amapola, el trillium, el lamium, la rosablanca, la campanilla, la dedalera, árboles como el espino, hierbas como el trébol, a través de su caminata por el bosque va revelando las singularidades de la vida, la muerte y la condición humana, donde la presencia de la luz a través de las rendijas de las copas de los árboles es reveladora de epifanías. Estos poemas son intercalados con símbolos místicos como los maitines y la escalera de Jacob, que aquí representa la transición de la vida a la muerte. Iris, también es el nombre con el que los antiguos griegos nominaban a una mensajera del Olimpo que descendía a la Tierra a través del arcoíris.

En Meadowlands (1997), Glück desarrolla un arco narrativo acerca del matrimonio de Ulises y Penélope, así como las consecuencias sobre Telémaco que vive entre la tensión de su padre ausente y las fantasías que teje su madre, este arco que da un salto cualitativo al mundo moderno para contar las ilusiones y desencuentros que ocurren en un matrimonio y un divorcio. Utilizando la parábola de los cisnes habla del amor masculino y femenino, para los hombres el amor es lo que se siente en el corazón mientras que para las mujeres el amor son las acciones.

\section{Odysseus'Decision $^{5}$}

"...Time begins now, in which he hears again

that pulse which is the narrative

sea, at dawn when its pull is strongest.

What has brought us here

will lead us away;

Mientras que en Vita Nova (1999), sus confesiones reviven el mito de Orfeo y Eurídice, para dar pie a hablar de la vida luego de una separación amorosa. "Nadie quiere ser la musa / finalmente todos quieren ser Orfeo...". Por ello se explica que tome prestado el título de una obra de Dante en la que habla del amor a Beattriz -Incipit vita nova- . "...Pensé que mi vida había terminado y mi corazón quedó roto/ entonces me mudé a Cambridge."

\section{Vita Nova}

"...Surely spring has been returned to me, this time not as a lover but a messenger of death, Yet it is still spring, it is still meant tenderly." 6

En el año 2000, Glück gana el Bollingen Prize for Poetry, otorgado por la Universidad de Yale y luego obtiene el Rosencranz writer-in-residence, así como una tarea como poeta consultora en la

5 El tiempo comienza ahora, cuando escucha nuevamente/ ese pulso que es la narrativa del mar/ al alba cuando aquel pulso es más fuerte. / Lo que nos trajo aquí/ nos sacará de aquí

6 Seguramente la primavera ha retornado a mí, esta vez/ no como amante sino como mensajera de la muerte/pero aún sigue siendo primavera, todavía significa algo tierno 
Biblioteca del Congreso de los Estados Unidos. En el año 2001 publicó The Seven ages

El lago Averno es un cráter volcánico localizado a casi 15 kilómetros de Nápoles, de acuerdo a los antiguos romanos aquel cráter era la puerta de ingreso al inframundo, un poco más allá de aquella entrada esperaba Caronte para embarcar a las almas recién llegadas. Glück aquí toma el mito de Perséfone para hablar de la trascendencia del alma más allá del cuerpo, de la iluminación, de las revelaciones de la poesía que nos alcanzan a entregar grandes verdades que a veces nos pueden doler. Averno (2006) se convierte en un contrapunto entre Hades y Démeter, madre de Perséfone, quien se deprime por el rapto de su hija, del egoísmo del dios que rapta a una mujer, de aquella joven que "...a diferencia del resto de nosotros/ no conoce lo que es el invierno, / solo qué es lo que lo causa." En la mitología, Perséfone era conocida como la diosa del inframundo, cuyas entradas y salidas del averno motivaba los cambios de ánimo de Démeter, diosa de la tierra, dando origen a las estaciones.

\section{Crater Lake}

There was a war between good and evil.

We decided to call the body good.

That made death evil.

It turned the soul

against death completely.

Like a foot soldier wanting

to serve a great warrior, the soul

wanted to side with the body.

It turned against the dark, against the forms of death

it recognized.

Where does the voice come from

that says suppose the war

is evil, that says suppose the body did this to us,

made us afraid of love- ${ }^{7}$

A village life (2009), a través de las viñetas de la vida en un pueblo del Mediterráneo, embarca sus narraciones entre el pulso de la naturaleza y los ciclos de la vida, más allá de su habitual ironía esboza algunos rasgos de optimismo. Glück, en los años siguientes obtuvo el National Book Award por Faithful and Virtuous Night y en 2016, Barack Obama le entregó el National Humanities Medal.

La literatura escarba entre los escombros de la humanidad para encontrar el germen que la hará renacer, una y otra vez. Si Shakespeare describió al universo dentro de una cáscara de nuez, Matsuo Basho encontró el misterio de la vida cuando una rana se tira al estanque, Christian Marlowe nos hizo saber que el infierno está en nosotros, Louise Glück nos cuenta en su poesía que los misterios de la vida (y la muerte) se pueden descubrir cuando la luz del sol cae sobre la hierba, unas veces para nutrirla, otras para marchitarla.

\section{Parodos $^{8}$}

"...I was born to a vocation:

to bear witness

to the great mysteries.

Now that I've seen both

birth and death, I know

to the dark nature these

are proofs, not

mysteries-"

7 Hubo una guerra entre el bien y el mal/ decidimos nombrar como bueno al cuerpo/ Esto hizo a la muerte la mala/ Y confrontó al alma/completamente contra la muerte/ Como a un simple soldado quiere / servir a un gran guerrero, el alma / quiso colocarse del lado del cuerpo. /Se volvió contra la oscuridad/ contra las formas de muerte/ que reconocía. / De dónde viene la voz / que dice, asume que la guerra / es mala, que dice/ asume que el cuerpo nos hizo esto, / ser temerosos del amor.

8 Nací con una vocación: / ser testigo/ de los grandes misterios. / ahora que vi ambos/ nacimiento y muerte. / Sé por esa naturaleza oscura que/ estas son pruebas, / no misterios. 
Bibliografía de Louise Glück

1968 Firstborn

1975 The House of Marshland

1976 The Garden

1980 Descending figure

1985 The triumph of Achilles

1990 Ararat*

1992 The Wild Iris*

1994 Proofs and Theories

1995 The Firts Four Bookks of Poems

1996 Meadowlands*

1999 Vita Nova*

2001 The Seven Ages*

2004 October

2006 Averno*

2009 A Village Life*

2012 Poems 1962-2012

2014 Faithful and Virtuous Night

2017 American Originality: Essays on Poetry

* Traducidos al español

\section{LECTURAS RECOMENDADAS}

Glück, Louise. https:/ / www.nobelprize.org / prizes / literature / 2020/ bio-bibliography /

Glück, Louise. Valencia: Editorial Pre-Textos.

_Ararat (2008)

_Averno (2011)

_El iris salvaje (2006)

_Las siete edades (2011)

_Praderas (2017)

_Una vida en el pueblo (2020)

_Vita Nova (2014)

\section{CORRESPONDENCIA:}

Aldo Vivar-Mendoza

aldo.vivar.m@upch.pe

Fecha de recepción: 13-03-2021.

Fecha de aceptación: 20-03-2021.

Conflicto de interés: ninguno, según el autor.

Financiamiento: por el autor.

Nota DEL EDITOR

Las traducciones de los poemas de Louise Glück, incluidas en los pies de página, del presente artículo han sido hechas por el autor del mismo. 